\title{
Magnetoelectric, magnetodielectric and magneto-impedance couplings in
} $\mathrm{Bi}_{1-\mathrm{x}} \mathrm{Nd}_{\mathrm{x}} \mathrm{Fe}_{0.99} \mathrm{Co}_{0.01} \mathrm{O}_{3}$ compounds

Acoplamentos magnetoelétricos, magnetodielétricos e magnetoimpedância em compostos

$\mathrm{Bi}_{1-\mathrm{x}} \mathrm{Nd}_{\mathrm{x}} \mathrm{Fe}_{0.99} \mathrm{Co0}_{0.01} \mathrm{O}_{3}$

Acoplamientos magnetoeléctricos, magnetodieléctricos y magneto-impedancia en compuestos

$\mathrm{Bi}_{1-\mathrm{xNd}} \mathrm{Fe}_{0.99} \mathrm{Co0}_{0.01} \mathrm{O}_{3}$

Received: 10/23/2021 | Reviewed: 10/30/2021 | Accept: 11/06/2021| Published: 11/10/2021

\author{
Anuar José Mincache \\ ORCID: https://orcid.org/0000-0001-8528-8020 \\ Universidade Estadual de Maringá, Brazil \\ E-mail: anuarfis@hotmail.com \\ Odair Gonçalves de Oliveira \\ ORCID: https://orcid.org/0000-0002-7522-9438 \\ Universidade Estadual de Maringá, Brazil \\ E-mail:odair_uem@hotmail.com \\ Lilian Felipe da Silva Tupan \\ ORCID: https://orcid.org/0000-0002-6766-1845 \\ Universidade Estadual de Maringá, Brazil \\ Centro Universitário Ingá, Brazil \\ E-mail: prof.liliantupan@uninga.edu.br \\ Daniel Matos Silva \\ ORCID: https://orcid.org/0000-0003-2202-4559 \\ Universidade Estadual de Maringá, Brazil \\ E-mail: danielmatos@dfi.uem.br \\ Ivair Aparecido dos Santos \\ ORCID: https://orcid.org/0000-0001-7775-0692 \\ Universidade Estadual de Maringá, Brazil \\ E-mail: iasantos@uem.br \\ Luiz Fernando Cotica \\ ORCID: https://orcid.org/0000-0003-2634-447X \\ Universidade Estadual de Maringá, Brazil \\ E-mail: 1fcotica@uem.br
}

\begin{abstract}
In this work $\mathrm{Bi}_{1-\mathrm{x}} \mathrm{Nd}_{\mathrm{x}} \mathrm{Fe}_{0.99} \mathrm{Co}_{0.01} \mathrm{O}_{3}$ ceramics compositions were synthesized for $\mathrm{x}=0.05,0.20$ and, $\mathrm{y}=0.01$. Structural refinement results show that most of the samples crystallized in a rhombohedral symmetry with R3c. Measurements magnetoelectric coefficient, show that the magnetoelectric coefficients are of second order. The electrical impedance characterization of in function external magnetic fields, has a relative variation of the real dielectric response, the loss tangent and the electrical impedance. The systems, as the DC magnetic field strength increased a gain in both the values of the dielectric constant variation, as well as the variation of the electrical impedance. In other words, the greater the intensity of the magnetic field, the greater your response. There were also significant variations with of the magnetic field AC.
\end{abstract}

Keywords: Ceramics; $\mathrm{BiFe}_{3}$; Non-linear magnetoelectric effect.

\section{Resumo}

Neste trabalho, as composições cerâmicas de $\mathrm{Bi}_{1-\mathrm{x}} \mathrm{Nd}_{\mathrm{x}} \mathrm{Fe}_{0.99} \mathrm{Co}_{0.01} \mathrm{O}_{3}$ foram sintetizadas para $\mathrm{x}=0,05,0,20 \mathrm{e}, \mathrm{y}=0,01$. Resultados de refinamento estrutural mostram que a maioria das amostras cristalizaram com simetria romboédrica R3c. As medições do coeficiente magnetoelétrico, mostram que os coeficientes magnetoelétricos são de segunda ordem. A caracterização da impedância elétrica de campos magnéticos externos em função, tem uma variação relativa da resposta dielétrica real, da tangente de perda e da impedância elétrica. Os sistemas, conforme a intensidade do campo magnético DC aumentaram um ganho tanto nos valores da variação da constante dielétrica, quanto na variação da impedância elétrica. Em outras palavras, quanto maior a intensidade do campo magnético, maior será sua resposta. Houve também variações significativas do campo magnético AC.

Palavras-chave: Cerâmica; $\mathrm{BiFe}_{3}$; Efeito magnetoelétrico não linear. 


\section{Resumen}

En este trabajo se sintetizaron composiciones cerámicas Bi1 - xNdxFe0.99Co0.01O3 para x = 0.05, 0.20 e, y =0.01. Los resultados del refinamiento estructural muestran que la mayoría de las muestras cristalizaron en una simetría romboédrica con R3c. Las mediciones del coeficiente magnetoeléctrico, muestran que los coeficientes magnetoeléctricos son de segundo orden. La caracterización de impedancia eléctrica de campos magnéticos externos en función, tiene una variación relativa de la respuesta dieléctrica real, la tangente de pérdidas y la impedancia eléctrica. Los sistemas, a medida que la intensidad del campo magnético de CC aumentaron una ganancia tanto en los valores de la variación de la constante dieléctrica, como en la variación de la impedancia eléctrica. En otras palabras, cuanto mayor sea la intensidad del campo magnético, mayor será su respuesta. También hubo variaciones significativas con el campo magnético AC.

Palabras clave: Cerámica; $\mathrm{BiFe}_{03}$; Efecto magnetoeléctrico no lineal.

\section{Introduction}

Materials that simultaneously exhibit ferroic properties, such as magnetism, ferroelectricity and ferroelasticity are classified multiferroics (Tokura, Seki \& Nagosa 2014) (Ramazanoglu et al 2011). The main applications invised these materials is in are sensors, spintronic among others (Bilmes et al 2000) (Wang et al 2003). Bismuth ferrite is a multiferroic because have two orders ferroic being called a magnetoelectric material. Is a promising material because it ferroeletric and magnetic room temperature, i.e. G-type antiferromagnetic order it has a transition of $640 \mathrm{~K}\left(\mathrm{~T}_{\mathrm{n}}\right)$, while the ferroelectric order appears at about $1100 \mathrm{~K}\left(\mathrm{~T}_{\mathrm{C}}\right)$. The $\mathrm{BiFeO}_{3}$ crystallizes in a rhombohedral perovskite structure with R3c (Fischei et al 1931). A of the problems shown by other authors is the appearance of unwanted phases in the process phase of bismuth ferrite (Hasan et al 2016). Some rare earth substitutions at the bismuth site $\left(\mathrm{La}^{+}, \mathrm{Gd} 3^{+}, \mathrm{Tb}^{+}, \mathrm{Dy} 3^{+}\right)$are reported by as an option to improve the electrical and magnetic properties of $\mathrm{BiFeO}_{3}$ ( $\mathrm{Li}$ et al 2013) (Fei et al 2015). A of the focus of this study is the dielectric measurements and impedances under action of an external magnetic field, classified as magnetodielectric and magnetoimpedance respectively. These phenomena have resumed the great demand for magnetic field sensitive materials and their range of applications (Phan \& Peng 2007). In this work, the $\mathrm{Bi}_{1-\mathrm{x}} \mathrm{Nd}_{\mathrm{x}} \mathrm{Fe}_{0.99} \mathrm{Co}_{0.01} \mathrm{O}_{3}$ system was processed three samples thickness in the $1.2 \mathrm{~mm}$ and $5.4 \mathrm{~mm}$ diameter to make the characterizations.

\section{Methodology}

This study was carried out in the materials science laboratory and is part of a research on the development of electronic devices capable of electrical and magnetic interaction. The samples were processed under the following conditions: the precursors were weighed and mixed in three stoichiometry. They then went through high energy ball milling at 250 rotation per minute (RPM) for one hour. All samples were pressed and baked for sintering at $890^{\circ}$ degrees for 3 minutes with rapid heating and cooling, called quenting (Shvartsman et al 2007). To check if the samples are in proper phases, X-ray diffraction was performed with Shimadzu diffractometer model XRD-7000, with scan rate of $2^{\circ} / \mathrm{min}$, from $10^{\circ}$ to $130^{\circ}$, in continuous mode at room temperature. From the x-ray diffraction, the refinement was performed using the Le Bail method, finding its network parameters. For dielectric measurements and electrical impedance under the magnetic field, an LCR meter (model E4980A), agilent function generator (model 33210A) and magnetic system (model GMW 5970-80) as shown in the measurement diagram of Figure 1.

The magnetodieletric and magneto-impedance measurements can be defined as $M D=\left|\frac{\varepsilon(H)-\varepsilon(0)}{\varepsilon(0)}\right| \times 100 \%$ and $M I=\left|\frac{Z(H)-Z(0)}{Z(0)}\right| \mathrm{x} 100 \%$ respectively. 
Figure 1: Diagram circuit used for the magnetodieletric and magneto-impedance measurement.

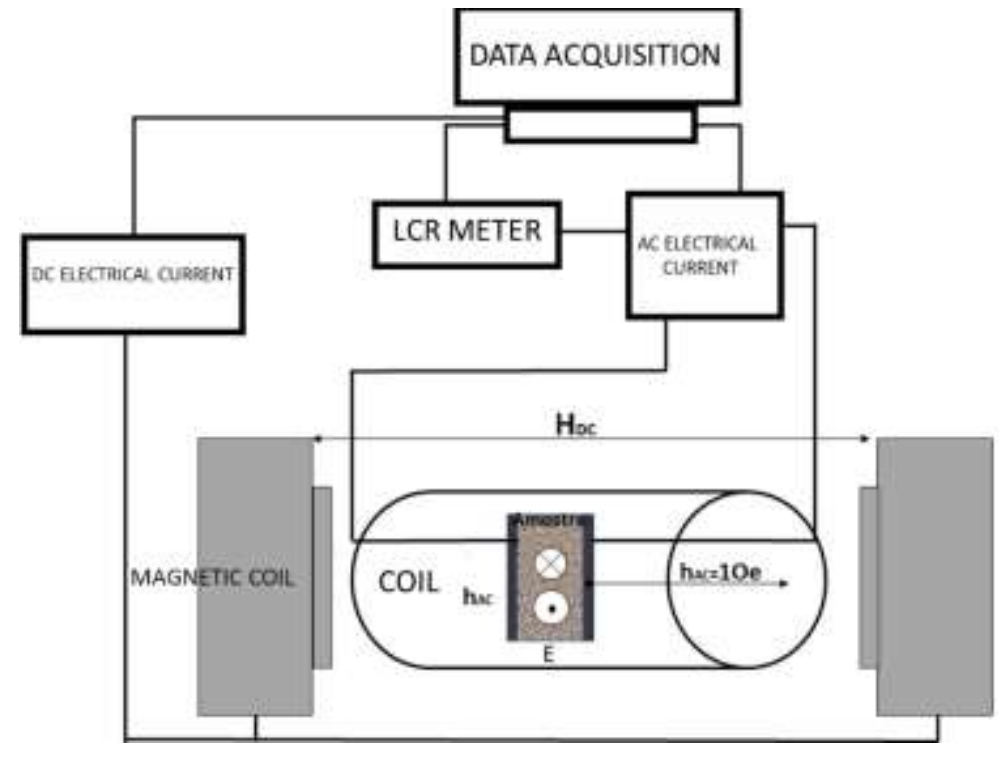

Source: Authors.

\section{Results and Discussion}

The results on x-ray diffraction and Le Bail refinement of Figure 2 showed results with the same phase described in the literature (Mincache et al 2016). According to the results of Le Bail refinement has the network parameters changing according to the doping. The sample volume a) has the larger volume then as neodymium increase the volume decreases, thus resulting in a phase change, noting also that noting also that $\chi^{2}$ in c) is above a good refinement. in c) is above a good refinement as show a Table 1 . Analyzing each diffractogram can see a change in peaks between angles of $31^{\circ}$ to $33^{\circ}$ degrees. It is possible that a structural change is taking place in the systems phase as already reported in other work (Singh et al 2017). The phase changes are happening in b) and c) of Figure 2, recent work (Oliveira 2015) has shown that these phases are rhombohedral and orthorobinch.

Table 1: Structural data of the rhombohedral phase obtained by the Le Bail method for the samples of $\mathrm{Bi}_{1-\mathrm{x}} \mathrm{Nd}_{\mathrm{x}} \mathrm{Fe}_{0.99} \mathrm{Co}_{0.01} \mathrm{O}_{3}$.

\begin{tabular}{|l|c|c|c|c|c|}
\hline $\mathbf{B i}_{1-\mathbf{x}} \mathrm{Nd}_{\mathbf{x}} \mathrm{Fe}_{0.99} \mathrm{Co0}_{0.01} \mathrm{O}_{3}$ & $\begin{array}{c}(\mathrm{a}=\mathrm{b}) \\
\AA\end{array}$ & $\begin{array}{c}(\mathrm{c}) \\
\AA\end{array}$ & $\begin{array}{c}\text { Space } \\
\text { Group }\end{array}$ & $\begin{array}{c}\text { x2 } \\
\text { Volume } \\
(\AA))^{\mathbf{3}}\end{array}$ \\
\hline $\mathrm{Bi}_{0.95} \mathrm{Nd}_{0.5} \mathrm{Fe}_{0.99} \mathrm{Co}_{0.01} \mathrm{O}_{3}$ & 5.569 & 13.832 & $\mathrm{R} 3 \mathrm{c}$ & 3.52 & 371.976 \\
\hline $\mathrm{Bi}_{0.80} \mathrm{Nd}_{0.2} \mathrm{Fe}_{0.99} \mathrm{Co}_{0.01} \mathrm{O}_{3}$ & 5.565 & 13.802 & $\mathrm{R} 3 \mathrm{c}$ & 6.52 & 369.771 \\
\hline
\end{tabular}

Source: Authors. 
Figure 2: Refinement by Le Bail method of the DRX standard of sample a) $\mathrm{Bi}_{0.95} \mathrm{Nd}_{0.5} \mathrm{Fe}_{0.99} \mathrm{Co}_{0.01} \mathrm{O}_{3}, \quad$ b) $\mathrm{Bi}_{0.80} \mathrm{Nd}_{0.2} \mathrm{Fe}_{0.99} \mathrm{Co}_{0.01} \mathrm{O}_{3}$.
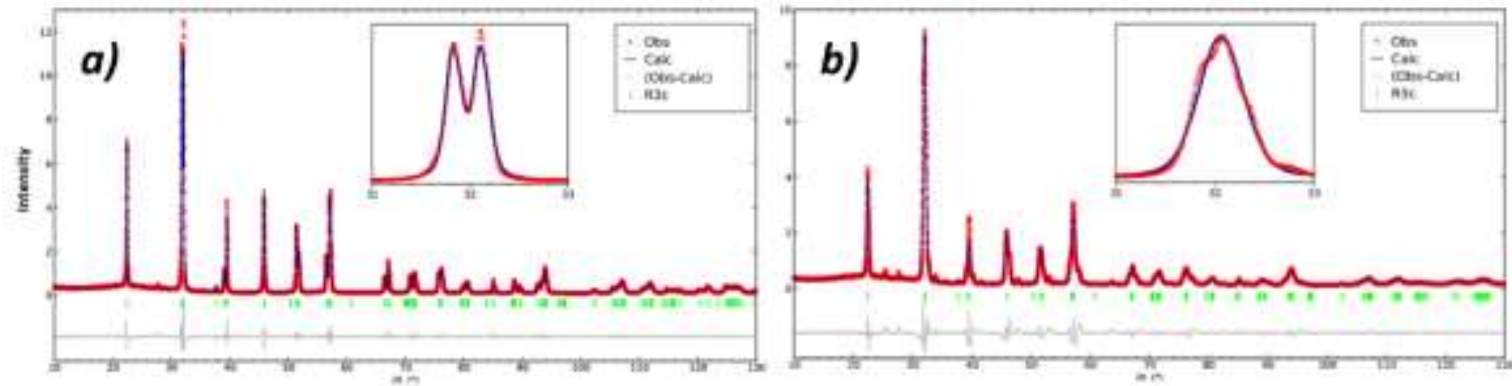

Source: Authors.

It can be seen from the magnetization (Figure 3) result that the compartment between the two samples is significant. when we add more neodymium sample with 20 percent becomes almost paramagnetic. A possible explanation for this phenomenon may be lone pair moving from its center of symmetry (Geng et al 2014), in which case the neodymium may be interfering with the magnetization of the system.

Figure 3: Magnetization curves at ambient temperature of samples $\mathrm{Bi}_{0.95} \mathrm{Nd}_{0.5} \mathrm{Fe}_{0.99} \mathrm{Co}_{0.01} \mathrm{O}_{3}, \mathrm{Bi}_{0.80} \mathrm{Nd}_{0.2} \mathrm{Fe}_{0.99} \mathrm{Co}_{0.01} \mathrm{O}_{3}$.

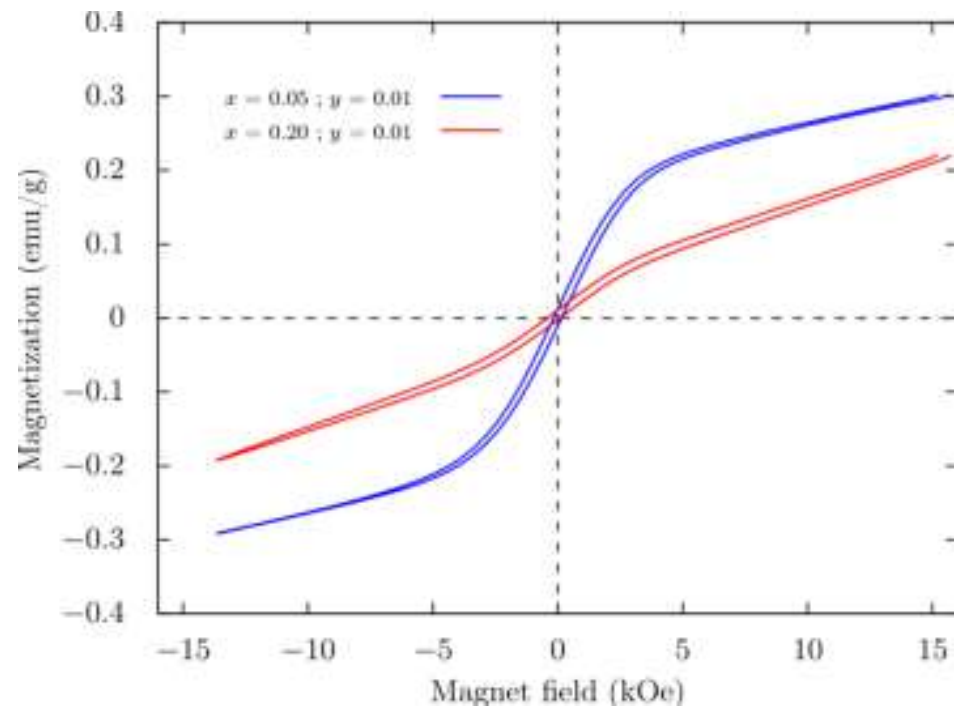

Source: Authors.

When a magnetic field is placed under a sample and its response with an electric voltage coefficient, it says that the material has a coupling between electricity and magnetism, so the material is magnetoelectric as shown in Figure 4 . The compartment of the two samples is observed to have similar shapes. The value of the magnetoelectric coefficient is low and becomes lower when we add more neodymium. A possible explanation for this effect is that the values of electro-striction and magneto-striction (Shen et al 2013) are not acting on the system in a linear way, but something more complex, such as the nonlinear magnetoelectric effect as reported in the works (Pirc \& Blinc 2010). 
Figure 4: Voltage variation under the applied magnetic field, a) $\mathrm{Bi}_{0.95} \mathrm{Nd}_{0.5} \mathrm{Fe}_{0.99} \mathrm{Co}_{0.01} \mathrm{O}_{3}$ and b) $\mathrm{Bi}_{0.80} \mathrm{Nd}_{0.2} \mathrm{Fe}_{0.99} \mathrm{Co}_{0.01} \mathrm{O}_{3}$.
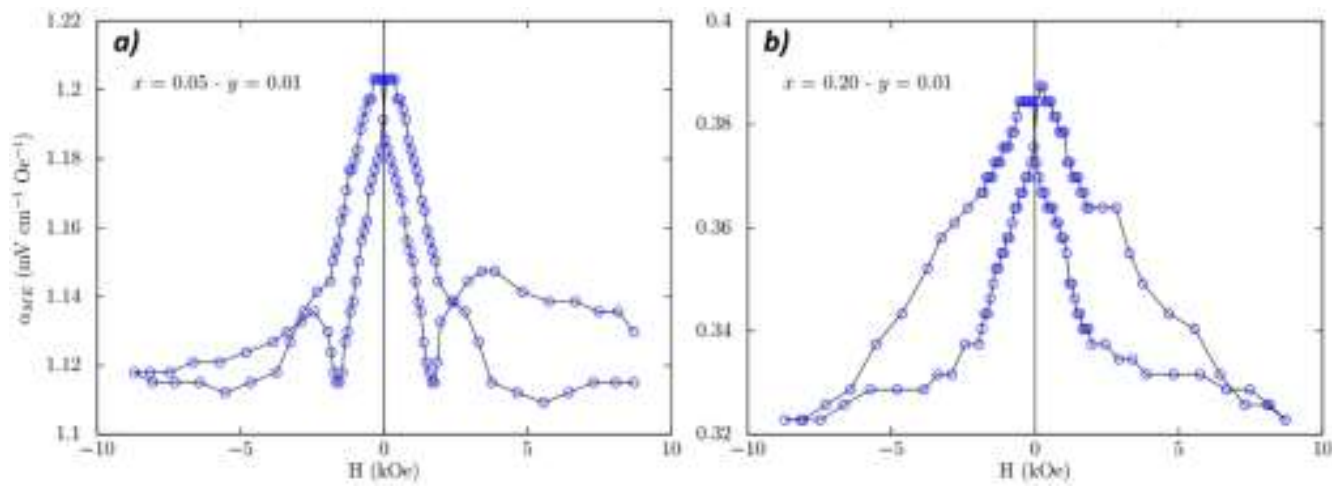

Source: Authors.

The magnetodielectric measurement is a dielectric constant as a function of the external magnetic field. $\Delta \varepsilon^{\prime}$ is the variation of the dielectric constant, $H_{D C}$ is the magnetic field between 1100 Oe and 8030 Oe plus the variation of the electric frequency $f_{E} 100,500$ and $1000 \mathrm{kHz}$ as show a Figure 5. Analyzing the graphs and even with a low response exhibit a variation in the dielectric constant when increasing the DC magnetic field. This happens for a) and b). For sample with $\mathrm{Bi}_{0.80} \mathrm{Nd}_{0.2} \mathrm{Fe}_{0.99} \mathrm{Co}_{0.01} \mathrm{O}_{3}$ has a small increase, certainly the neodymium is influencing the electrical properties of the system. This phenomenon can be seen in the paper (Rana et al 2019) (Basu et al 2019) which shows the variation of the dielectric constant under a magnetic field.

Figure 5: Variation of the dielectric constant under the applied magnetic field a) $\mathrm{Bi}_{0.95} \mathrm{Nd}_{0.5} \mathrm{Fe}_{0.99} \mathrm{Co}_{0.01} \mathrm{O}_{3}$ with magnetic field DC 1100 Oe and 8030 Oe and b) $\mathrm{Bi}_{0.80} \mathrm{Nd}_{0.2} \mathrm{Fe}_{0.99} \mathrm{Co}_{0.01} \mathrm{O}_{3}$ with magnetic field DC 1100 Oe and 8030 Oe.
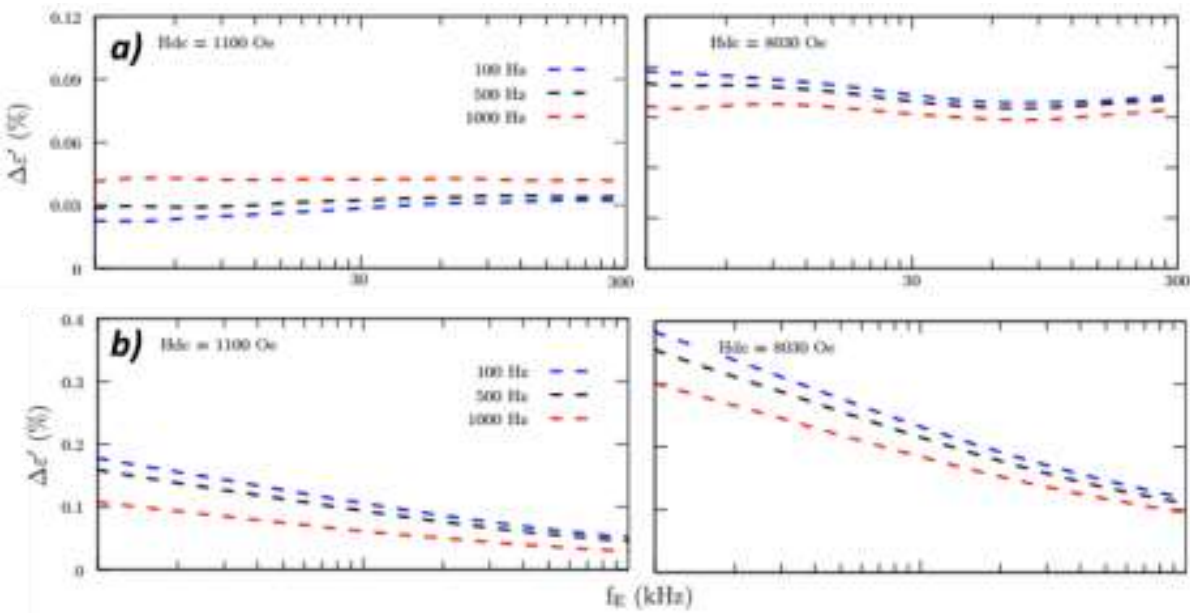

Source: Authors.

The electrical impedance measurements follow the same scheme as the magnetodielectric measurement (Figure 6). 
Figure 6: Variation of the impedance electric under the applied magnetic field a) $\mathrm{Bi}_{0.95} \mathrm{Nd}_{0.5} \mathrm{Fe}_{0.99} \mathrm{Co}_{0.01} \mathrm{O}_{3}$ with magnetic field DC 1100 Oe and 8030 Oe and b) $\mathrm{Bi}_{0.80} \mathrm{Nd}_{0.2} \mathrm{Fe}_{0.99} \mathrm{Co}_{0.01} \mathrm{O}_{3}$ with magnetic field DC 1100 Oe and 8030 Oe;

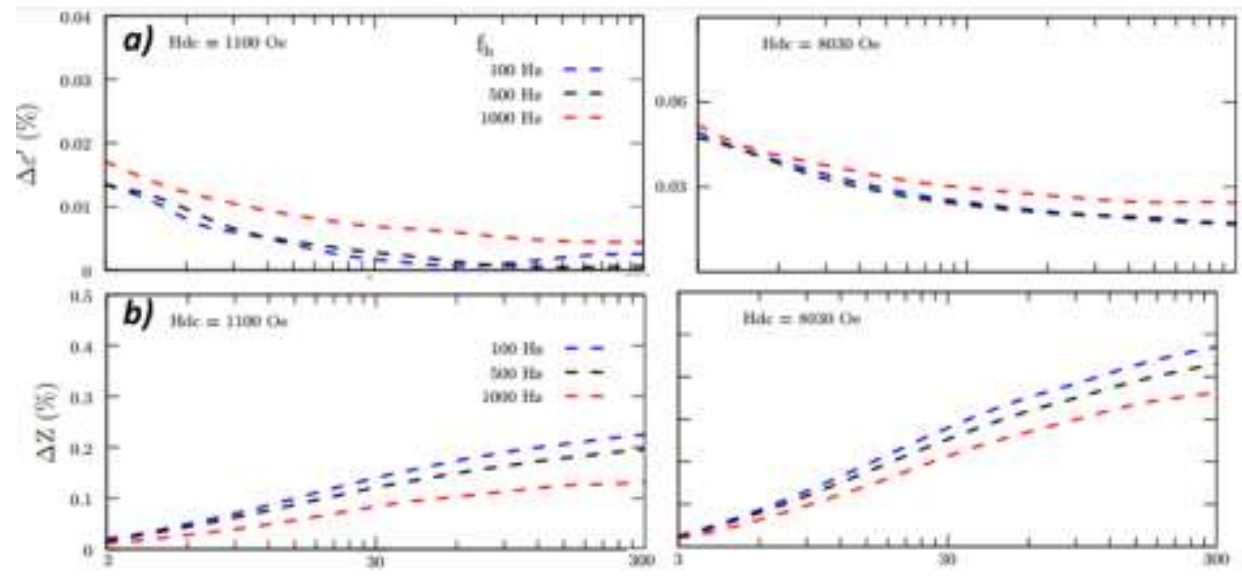

Source: Authors.

Analyzing the graphs, even having a low response, the variation of the electrical impedance happens when the DC magnetic field increases. The difference between the two samples is at the beginning of the measurement, in sample a) it starts with a value and decreases with the increase of the electric frequency. b) starts at zero and constantly increases with increasing magnetic field DC (Kammouni et al 2016) (Chizhik et al 2017). Indeed, when a magnetic field is under sample it responds with the change in electrical impedance (Li, Kavaldzhiev \& Kosel 2015) (Liu et al 2012).

\section{Conclusion}

With the results of x-ray diffraction and refinement observed in the sample with $5 \%$ of neodymium a phase R3c. In the second sample with $20 \%$ neodymium it is possible that its structure is changing to another phase, possibly orthorhombic. and when we add more neodymium to the system it becomes more paramagnetic. Magnetoelectric results possibly show a nonlinear effect. Regarding the magnetodielectric and magneto-impedance measurements it can be observed that their nominal values increase when the DC magnetic field is increased, however this happens with the addition of neodymium.

\section{References}

Bilmes S. A., Mandelbaum P., Alvarez, F. \& Victoria N. M. (2000). Surface and Electronic Structure ofTitanium Dioxide Photocatalysts, 104, 9851-9858.

Chizhik A., Vega V., Mohamed A. E.-M. A., Prida V., Sánchez T., Hernando B., Ipatov M., Zhukova V., Zhukov A., Stupakiewicz A., Domínguez L., \& González J. (2017). Surface magnetic properties and giant magnetoimpedance effect in co-based amorphous ribbons. Intermetallics, 86, 15-19.

de Oliveira O. G. (2015). Refinamento Estrutural e Cálculos de Densidade Eletrônica no Sistema Multiferróico (Bi1-xNdx)(Fe1-yCoy)O3. Dissertação de Mestrado, Universidade Estadual de Maringá, Maringá.

Fei L., Hu Y., Li X., Song R. et al. (2015). Electrospun bismuth ferrite nanofibers for potential applications in ferroelectric photovoltaic devices Acs Applied Materials and Interfaces 7, 3665 .

Fischei, P, Polemska, M, Sosnowska, I \& Szymanski, M (1931). Temperature dependence of the crystal and magnetic structures of BiFeO3 1980 J. Phys. C 13,1931 .

Geng Y., et al (2014). Direct visualization of magnetoelectric domains, Nature Materials, 13, 163-167.

Hasan M., Islam M. F., Mahbub R., Hossain M. S \& Hakim, M. A (2016). A soft chemical route to the synthesis of BiFeO3 nanoparticles with enhanced magnetization. Boletim de Pesquisa de Materiais 73, 179

Kammouni R. E., Kurlyandskaya G., Vázquez M., \& Volchkov S. (2016). Magnetic properties and magnetoimpedance of short CuBe/CoFeNi electroplated microtubes. Sensors and Actuators A: Physical, 248, 155-161. 
Research, Society and Development, v. 10, n. 14, e470101422189, 2021

(CC BY 4.0) | ISSN 2525-3409 | DOI: http://dx.doi.org/10.33448/rsd-v10i14.22189

Li B., Kavaldzhiev M. N., \& Kose, J. (2015). Flexible magnetoimpedance sensor. Journal of Magnetism and Magnetic Materials, vol. 378 , pp. 499-505.

Li B., Wang C., Liu W., Ye M. \& Wang N. (2013). Magnetic and Photocatalytic Behaviors of Ca Mn Co-Doped BiFeO3 Nanofibres. Materials Letters ,90, 45 .

Liu Y., Yao Y., Dong S., Jiang T., Yang S., \& Li X. (2012). Colossal magnetocapacitance effect in BiFeO3/La5/8Ca3/8MnO3 epitaxial films. Thin Solid Films, 520(17), 5775-5778.

Mincache, A. J., et al (2016). Evidencing the magnetoelectric coupling in Bi1-xNdxFeO3 compositions through ferroic characterizations. Integr. Ferroelectr. 174 pp. $98-103$.

Phan M. H., \& Peng H. X. (2008). Giant magnetoimpedance materials: fundamentals and applications, Prog. Mater. Sci. 53, 323e420, https://doi.org/10.1016/ j.pmatsci.2007.05.003

Pirc R. \& Blinc R. (2010). Nonlinear magnetoelectric effect in magnetically disordered relaxor ferroelectrics. Ferroelectrics, 400(1), 387-394.

Ramazanoglu M., Ii W.R., Choi Y.J., Lee S., Cheong S., \& Kiryukhin V. (2011). Temperature-dependentproperties of the magnetic order in single-crystal $\mathrm{BiFeO}, 174434,1-6$

Rana D. K., Kundu S. K., Choudhary, R. J. \& Basu,1 (2019). Enhancement of electrical and magnetodielectric properties of BiFeO3 incorporated PVDF flexible nanocomposite films. Published IOP Publishing Ltd.

Shen Y., Gao J., Wang Y., Finkel P., Li, J. \& Viehland D. (2013). Piezomagnetic straindependent non-linear magnetoelectric response enhancement by flux concentration effect. Applied Physics Letters, 102(17), 172904.

Shvartsman V. V., Kleemann W., Haumont R., \& Kreisel J. (2007). Large bulk polarization and regular domain structure in ceramic BiFeO3. Applied Physics Letters, 90(17), 172115.

Singh O., A. Agarwal, Amitabh Das, \& Sanghi S., Jinda A. (2017). Evolution of structural and magnetic phases in Nd doped BiFeO3 multiferroics with sintering time. 442, 200-207.

Tokura Y., Seki S., \& Nagaosa N. (2014). Multiferroics of spin origin. Reports on Progress in Physics 77(7), 76501.

Wang, J., et al (2003). Effect of Ba Substitution on the Structural and Magnetic Properties of BiFeO3 Science (New York, N.Y.) $299(5613) 1719$. 